Syntactic features were seldom mentioned (and then sometimes wrongly) and elementary semantic features-such as (animate), (evaluative)-are also lacking in the protocols. Ss seem to have been trying to give synonyms for words, and so the protocols contain only distinguishers, which presumably have a maximal number of semantic markers in common with the target words. Sometimes phonetic or "syntagmatic" clues are given. An illustrative selection of protocols follows, with the target word in capitals, and guesses in brackets:

YOUTH: boy (girl), young (infant), -hostel (youth).

DOCILITY: quiet, still (dead), used of animals, tranquil (placid, calm), try again (peaceful), especially normally aggressive animals, female deer sound (doe), second part like smile (docile), same part of speech as tranquility (docility).

WRONG: not right (wrong).

ERRATIC: sudden actions (impulses), jerky, not uniform (irregular), like Joe, may be neurotic. (Not guessed.)

TAKE: steal (rob, pilfer, remove), -away (take).

REVERE: look up to (admire), respect (appreciate), as in a vicar (reverend), verb (revere).

NEXT: one after (next).

SUPREMELY: uppermost (top), best (elite), well done, very well done (excellent), his-highness (royal), pinnacle (peak), extremely. (Not guessed.)

\section{DISCUSSION}

The communication technique used in this experiment must be considered a failu re - as a method of externalizing dictionary entries.

The variation between words of different form-class with respect to communicability and the ease with which they can be defined may be compared with other observations. Miller (1968) finds that parts of speech other than nouns are not grouped together in ways that a dictionary-entry theory might account for. Fillenbaum (1964) showed that words of ambiguous form-class were semantically satiated and more rapidly when they functioned as adverbs than when they functioned as nouns, the former, it was argued, being more dependent on context for their meaning. Deese (1962) has shown that words of different form-class vary in the likelihood of eliciting paradigmatic word associations. Nouns are most likely and adverbs least likely to elicit paradigmatic associations, with verbs and adjectives intermediate; also, high-frequency adjectives are more likely than low-frequency adjectives to elicit paradigmatic associations. Deese argues that these findings can be explained by a hypothesis that the types of words most likely to elicit paradigmatic associations are those least dependent on their verbal contexts. Nouns seem to appear first in speech development. The author's daughter, for example, at the age of 24 months had a vocabulary of probably well over 100 names-for-things before the first handful of adjectives and names-for-actions appeared; no adverbs had appeared at this time or in the ensuing 3 months. Nouns may be more resistant to aphasic impairment than other form-classes: a paralexic studied by Marshall \& Newcombe (1966) had less difficulty in encoding correctly the form-class of nouns than of verbs, with adjectives intermediate

The evidence suggests that nouns are relatively context-independent, are acquired earliest, and are lost least readily; adverbs are least robust and most context-dependent adjectives and verbs are intermediate. In view of this, the findings of the present experiment in which adverbs and low-frequency words are difficult to define and to communicate supports the idea that the meanings, whatever their nature, of certain words do not perhaps exist as separately stored entities for each lexical item.

\section{REFERENCES}

BROWN, R., \& MCNEILL, D. The tip-of-the-tongue phenomenon. Journal of Verbal Learning \& Verbal Behavior, 1966, 5, 325-337.
Dl:IESE, J. fiorm-class and the determinamts of asiociation. Journal of Verbal Learning \& Verbal Behavior. 1962. 1. 79-84.

DEESE, J. The stricture of associatire meaning. Baltinore: Johns Hopkins Press. 1965.

FILLENBAUM. S. A turther study of grammatical class as a variable in verbal satiation. Language \& Speech, 1964, 7, 233-237.

KATZ, J. J., \& FODOR, J. A. The structure of a semantic theory. Language, 1963, 39, 170-210.

MARSHALL, J. C., \& NEWCOMBE, IF. Syntactic and semantic errors in paralexia. Neuropsychologia, 1966, 4, 169.

MILLER, G. A. Algebraic models in psycholinguistics (summarized by R. Goodwin). In C. Vlek (Ed.), Algebraic models in psychology. Proceedings of the NUFFIC International Summer Session in Science, The Hague. August 1968. Pp. 161-224.

NOBLE, C. E. An analysis of meaning. Psychological Review, 1952,59,421-430.

OSGOOD, C. E., SUCI, G., \& TANNENBAUM,P. The measurement of meaning. Urbana. Ill. Univeristy of Illinois Press. 1957.

RAZRAN, G. H. A quantitative study of meaning by a conditioned salivary technique (semantic conditioning). Science, 1939, 90, 89-90.

SIEGEL, S. Nonparametric statistics. New York: McGraw-Hill, 1956.

THORNDIKE, E. 1., \& LORGE, I. The teacher's word book of 30.000 words. New York: Columbia University Press. 1944.

\section{NOTE}

1. Thanks are due to Roger Goodwin, Department of Psychology, University College. London, for helpful discussions of this experiment.

\title{
Relation of mental ability to preference for varying rates of auditory stimulation 1
}

JAMES E. LERI and NORMAN J. LESSWING, Allegheny College, Meadville, Pa. 16335, and MERRILL F. ELIAS, ${ }^{2}$ Duke University, Center for the Study of Aging and Human Development, Durham, N.C. 27706

Preferences for varying rates of auditory stimulation were compared for three groups: (a)older $S s$ of average $I Q$, (b) younger $S$ s of average $I Q$, and (c) older retarded Ss. All possible pairs of eight different auditory rates, consisting of differing numbers of tones per $10-\mathrm{sec}$ period, were presented. Younger $S s$ of average $I Q$ showed a greater preference for the highest rates of stimulation than the older Ss. Preferences of older retardates were more similar to younger Ss.

Knowledge of the relationship between mental ability (MA) and preference for varying rates of stimulation may be important for an understanding of the role of motivational or activation mechanisms in the retardate's adjustment to his environment. There have been few, if any, studies of this relationship, but Boesch, Baltes, \& Schmidt (1968) have reported marked differences in preference for different rates of auditory stimulation among Ss of different ages. The relationship between number of tones per 10-sec period (rate of stimulation) and preference was essentially curvilinear for Ss from 12 to 20 years. They showed an increased preferenec 
for higher rates of stimulation up to a point, followed by decreased preference for the highest rates of stimulation. In contrast, the relationship between stimulus rate and preference was approximately linear for 8to 10-year-old Ss. The same results were obtained in a later experiment (Baltes, Schmidt, \& Boesch, 1968) with visual stimulation.

Since the effects of MA were not directly manipulated in the Boesch et al and the Bal tes et al experiments, and since a number of experiments (Ellis, 1963) indicate that retardates behave in ways which are similar to younger children of "normal" intelligence, it seemed logical to expect that MA, rather than chronological age (CA), would play the critical role in preference for stimulation.

\section{METHOD}

Noninstitutionalized male Ss were obtained from local school systems and a sheltered workshop. IQs of Ss in the average range of intelligence had been defined by either the Pintner-Cunningham Primary Test or the Otis Beta. IQs for the retardates had been defined by either the Stanford-Binet or the WAIS. Diagnostic records revealed no evidence of brain damage or hearing abnormalities. Three groups were used: (1) a younger-average group $(\mathrm{N}=27)$, with a mean CA of 8.2 (range $7-8$ to $8-5$ ); (2) an older-average group $(\mathrm{N}=30)$, with a mean CA of 17-11 (range 16-11 to 20-2); (3) an older-retarded group $(\mathrm{N}=21)$, with a mean CA of $17-5$ (range $16-3$ to 20-11). The older-retarded and older-average groups were matched as closely as possible for CA. Older-average and younger-average groups were matched as closely as possible for IQ. Mean IQs were 101 (range 95 to 106) and 104 (range 96 to 112) for the two respective groups. The older-retarded group had a mean IQ of 67 (range 60 to 73). Ss in the low end of the borderline IQ classification were included in the older-retarded group because of the limited number of Ss available for the experiment. A lower limit of $60 \mathrm{IQ}$ was established, since pilot work indicated that Ss with lower IQs could not understand the instructions no matter how simply they were stated. Since a lower limit of 60IQ was used, it was not possible to match $S s$ in the younger-average and the older-retarded groups in terms of MA.

Using the pair-comparisons method, Ss were presented with the same 28 possible pairs of the eight auditory rates used by Boesch et al, ${ }^{3}$ i.e., $3,5,8,13,22,37,61$, and 100 tones per 10 -sec period. They were presented under the same conditions, except: (1) Boesch et al retested Ss after 1 week, while the present Ss were tested once; (2) Ss were tested in groups of one to four as scheduling permitted: (3) the stimuli were presented via earphones. There were $3 \mathrm{sec}$

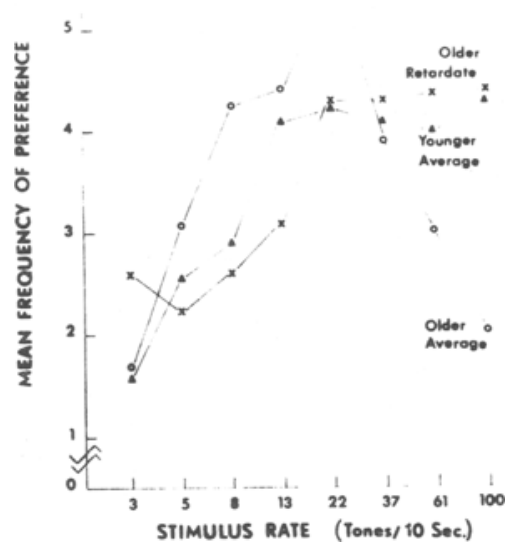

similar preferences (see Fig. 1) and differed markedly from the older-average group. Observed differences for the 8-, 13-, 22-, 61 -, and 100-tone conditions ( $\mathrm{df}=2$ ) were all significant with Kruskal-W'allis (Siegel, 1956, pp. 184-193) $\mathrm{H}$ values of 13.92 $(p<.05), 6.48(p<.05), 14.78(p<.001)$, $8.68(p<.01)$, and $13.80(p<.001)$. Es offer no explanation for the deviation from the general trend of similarity for the older-retarded group and the younger-average group at the 13-tone condition.

The present finding that older retardates, like younger children of average IQ, show preferences for higher rates of stimulation than older Ss of average IQ suggests that MA is more critical to stimulus preference than CA per se. The reasons why are not clear. Boesch et al have interpreted decreased preference for higher stimulus rates in older Ss in terms of a reduction in external stimulation to compensate for increased internal stimulation accompanying individual development. Perhaps the retardate's level of internal stimulation is lower than the "normal" S's. Consequently, he prefers higher levels of external stimulation. Unfortunately, the literature (Duffey, 1962; Glanzer, 1958; Fiske \& Maddi, 1961) provides neither clear agreement concerning exact causes of lowered internal stimulation nor an exact definition of internal stimulation.

\section{REFERENCES} (Siegel, 1965, pp. 116-125) indicated that observed differences in preference among the eight auditory stimulus rate conditions were statistically significant for all three groups: older-average $\left(\chi_{\mathrm{r}}=72.37, \mathrm{df}=7\right.$, $\mathrm{p}<.001) ;$ younger-average $\left(\chi_{r}=32.17\right.$, df $=7, p<.001) ; \quad$ older-retarded $\left(x_{\mathrm{r}}=26.58, \mathrm{df}=7, \mathrm{p}<.001\right)$. Consistent with Baltes et al and Boesch et al findings, there was an approximate inverted $\mathrm{V}$-shaped relation between preference and stimulus rate for the older-average group, i.e., preference for higher rates of stimulation increased up to 22 tones and then decreased to 100 tones. Data for the present younger-average group (mean $\mathrm{CA}, 8-2$ ) are not consistent with Baltes et al and Boesch et al findings for 8-year-old males. They found a generally increasing preference for higher levels of stimulation from 3 to 100 tones and flashes, respectively. The present findings are, however, consistent with Baltes et al's and Boesch et al's major finding of decreasing preference for higher rates of stimulation with increased $\mathrm{CA}$, i.e., the younger-average group showed a higher preference for the 61-and 100-tone stimulus rate than did the older-average group.

With exception of the 3- and 13-tone conditions, the older-retarded and the younger-average groups showed strikingly
BALTES, P. B., SCHMIDT, L. R., \& BOESCH, E. B. Preference for different visual stimulus sequences in children, adolescents, and young adults. Psychonomic Science, 1968, 11, 271-272.

BOESCH, E. B., BALTES, P. B., \& SCHMIDT, L. R. Preferences for different auditory stimulus sequences in various age groups. Psychonomic Science, 1968, 10, 205-206.

DUFFEY, E. Activation and behavior. New York: Wiley, 1962.

ELLIS, N. R. (Ed.), Handbook of mental deficiency. New York: McGraw-Hill, 1963.

GLANZER, M. Curiosity, exploratory drive, and stimulus satiation. Psychological Bulletin, $1958,55,302-315$.

FISKE, D. W., \& MADDI, S. R. Functions of varied

SIEGEL, S. Nonparametric statistics for the behavioral sciences. New York: McGraw-Hill, 1956.

\section{NOTES}

1. Appreciation is expressed to Dr. G. Barber (Erie, Pennsylvania School System), Mr. R. Bacher (Vallonia Industries, Pa.), Dr. G. Frisk and Mr. J. O'Mara (Western State School and Hospital, $\mathrm{Pa}$.), Dr. J. Hall (Polk State School and Hospital, Pa.), and Mr. R. Wick (Meadville, Pennsylvania School System) for help in procuring $S s$ for this experiment and unpublished pilot work.

2. Please address correspondence concerning this experiment to the third author. The first two authors performed this experiment as part of an undergraduate independent study.

3. The authors wish to thank P. B. Baltes, E. B. Boesch, and L. R. Schmidt for providing a tape of their stimuli. experience. Honewood: Dorsey Press, 1961. 